\title{
Cerebellar Defects in $\mathrm{Ca}^{2+} /$ Calmodulin Kinase IV-Deficient Mice
}

\author{
Thomas J. Ribar, ${ }^{1}$ Ramona M. Rodriguiz, ${ }^{2}$ Leonard Khiroug, ${ }^{3}$ William C. Wetsel, ${ }^{2}$ George J. Augustine, ${ }^{3}$ \\ and Anthony R. Means ${ }^{1}$ \\ Departments of ${ }^{1}$ Pharmacology and Cancer Biology, ${ }^{2}$ Psychiatry and Behavioral Sciences, Medicine, and Cell Biology, \\ and ${ }^{3}$ Neurobiology, Duke University Medical Center, Durham, North Carolina 27710
}

\begin{abstract}
The $\mathrm{Ca}^{2+} /$ calmodulin-dependent protein kinase CaMKIV was first identified in the cerebellum and has been implicated in nuclear signaling events that control neuronal growth, differentiation, and plasticity. To understand the physiological importance of CaMKIV, we disrupted the mouse Camk4 gene. The CaMKIV null mice displayed locomotor defects consistent with altered cerebellar function. Although the overall cytoarchitecture of the cerebellum appeared normal in the Camk4 ${ }^{-1-}$ mice, we observed a significant reduction in the number of mature Purkinje neurons and reduced expression of the protein marker calbindin D28k within individual Purkinje neurons. Western immunoblot analyses of cerebellar extracts also established sig-
\end{abstract}

The family of multifunctional $\mathrm{Ca}^{2+} /$ calmodulin-dependent protein serine/threonine kinases (CaMKs) includes CaMK types I-IV and the recently discovered CaMKKs (Schulman and Braun, 1999; Means, 2000). One of these enzymes, CaMKIV, was first identified in cerebellar granule cells (Ohmstede et al., 1989), and subsequent studies showed that CaMKIV was also present in cerebellar Purkinje cells, other neurons, T lymphocytes, and postmeiotic male germ cells (Frangakis et al., 1991; Jensen et al., 1991; Means et al., 1991).

CaMKIV is predominantly a nuclear enzyme, and functional studies have suggested a role for this kinase in the phosphorylation of serine-133 and activation of transcription by cAMP response element-binding protein (CREB) (Matthews et al., 1994). Indeed, CaMKIV associated with the protein serine/threonine phosphatase PP2A is thought to function as a regulatory module that controls CREB-mediated transcription in response to changes in nuclear $\mathrm{Ca}^{2+}$ concentration (Westphal et al., 1998). This in turn leads to transcriptional activation of immediate early genes of the fos and jun families (Bito et al., 1996; Chawla et al., 1998), and neurotrophins such as brain-derived neurotrophic factor (Shieh et al., 1998), which may regulate neuronal growth and development. CaMKIV also appears to control transcription of the orphan nuclear receptor nur-77 (Youn et al., 1999), as well as to enhance transcription mediated by other orphan receptors, including $\operatorname{ROR} \alpha, \operatorname{ROR} \gamma$, and COUP-TF1 (Kane and Means, 2000). However, the cascade of signaling events responsible for these effects of CaMKIV remains to be elucidated.

The CaM kinases have long been implicated in the regulation

Received July 7, 2000; revised Aug. 29, 2000; accepted Aug. 31, 2000.

This work was supported by grants from the National Institute of Health to A.R.M., W.C.W., and G.J.A. W.C.W. also receives support from the March of Dimes Birth Defects Foundation and the National Alliance for Research on Schizophrenia and Depression. We thank Cheryl Bock of the Duke Comprehensive Cancer Center Transgenic and Knockout Mouse Facility for generating the null mice. We are also grateful to Shirish Shenolikar, John Conner, and Don Pfaff for many helpful discussions and critical evaluation of this manuscript.

Correspondence should be addressed to Dr. Anthony R. Means, Department of Pharmacology and Cancer Biology, Duke University Medical Center, P.O. Box 3813, Durham, NC 27710. E-mail: means001@mc.duke.edu.

Copyright (C) 2000 Society for Neuroscience $0270-6474 / 00 / 200001-05 \$ 15.00 / 0$ nificant deficits in the phosphorylation of cAMP response element-binding protein at serine-133, a proposed target of CaMKIV. Additionally, the absence of CaMKIV markedly altered neurotransmission at excitatory synapses in Purkinje cells. Multiple innervation by climbing fibers and enhanced parallel fiber synaptic currents suggested an immature development of Purkinje cells in the Camk4 ${ }^{-1-}$ mice. Together, these findings demonstrate that CaMKIV plays key roles in the function and development of the cerebellum.

Key words: calcium; calmodulin kinase IV; knock-out mice; cerebellum; Purkinje cells; differentiation

of synaptic activity. Disruption of the mouse CamkII $\alpha$ gene established the role of this kinase in synaptic events involved in the acquisition of certain types of spatial memory (Silva et al., 1992). Likewise, CaMKIV has been implicated in the late phases of synaptic plasticity associated with the consolidation of certain types of memory formation (Bito et al., 1996; Masaaki et al., 1997; Ahn et al., 1999). However, unlike other members of the CaMK family, CaMKIV has a restricted pattern of expression that is regulated during development (Ohmstede et al., 1989; Jensen et al., 1991), suggesting that CaMKIV may have different functions in distinct populations of cerebellar neurons.

To examine the role of CaMKIV in the mammalian brain, we have generated mice lacking the Camk4 gene. Behavioral analyses of these mice established the presence of tremors, altered gait, and moderate to severe loss of motor control, consistent with cerebellar defects. Morphological studies indicated a loss of cerebellar Purkinje neurons, whereas biochemical analyses established the reduced expression of calbindin D28k and defective nuclear signaling to CREB. Electrophysiological studies also demonstrated significant defects in synaptic transmission at excitatory synapses of Purkinje neurons in Camk4 ${ }^{-1-}$ mice. Together, our results establish an important role for CaMKIV in cerebellar function and development.

\section{MATERIALS AND METHODS}

Generation of Camk4 $4^{-/-}$mice. The CaMKIV gene was disrupted in mice via homologous recombination as described previously (Wu et al., 2000).

This article is published in The Journal of Neuroscience, Rapid Communications Section, which publishes brief, peer-reviewed papers online, not in print. Rapid Communications are posted online approximately one month earlier than they would appear if printed. They are listed in the Table of Contents of the next open issue of JNeurosci. Cite this article as: JNeurosci, 2000, 02:RC107 (1-5). The publication date is the date of posting online at www.jneurosci.org.

http://www.jneurosci.org/cgi/content/full/4718 
Western blotting. Western blots were performed as outlined previously (Anderson et al., 1997) using either 150 or $25 \mu \mathrm{g}$ of cerebellar protein from age-matched $\mathrm{Camk}^{+/+}, \mathrm{Camk}^{+/-}$, and Camk4 ${ }^{-1-}$ postpubertal littermates. Antibodies were obtained from the following sources: antiCaMKIV and anti-CaMKK (Transduction Laboratories, Lexington, KY), anti-CaMKII $\alpha$ (Boehringer Mannheim, Indianapolis, IN), antiCaMKI (generated by Sara Hook, laboratory of A. R. Means), anti-PKA and anti- $\alpha$-tubulin (Santa Cruz Biotechnology, Santa Cruz, CA), and anti-CREB and anti-phosphorylated CREB (pCREB) (Upstate Biotechnology, Lake Placid, NY).

Immunocytochemistry. Immunocytochemistry was performed as described previously (Jensen et al., 1991). Cerebella were formalin-fixed and embedded in paraffin, and $6 \mu \mathrm{m}$ coronal sections were cut on a rotary microtome. Sections subjected to immunocytochemistry were visualized by either an IgG-rhodamine conjugate (Jackson ImmunoResearch, West Grove, PA) or the ABC method (Vector Laboratories, Burlingame, CA). General tissue morphology was visualized by staining with $0.05 \%$ cresyl violet.

Behavioral analyses. Tests for ataxia or gait were evaluated by the foot-printing method. Landmarks were established as described previously (Robbins, 1985), and the length, width, and angle of foot deflection were compared for wild-type (WT) and Camk4 ${ }^{-1-}$ animals. Linear strides of five or more matched footprints were used for these analyses. Spontaneous locomotor activity was measured in an automated Omnitech Digiscan apparatus (AccuScan Instruments, Columbus, $\mathrm{OH}$ ) under illuminated conditions. Evaluations of muscle strength, motor reflexes, and gross body coordination were performed by established methods (Rogers et al., 1997; Paylor et al., 1998). Sensorimotor skills were studied using a rotorod (Stoelting, Wood Dale, IL) with accelerating (4-40 rpm over $5 \mathrm{~min})$ and constant-speed $(25 \mathrm{rpm})$ protocols administered on successive days. Trials were terminated by either a passive rotation, when the animal fell from the rod, or at $300 \mathrm{sec}$. Mice received five trials separated by $15 \mathrm{~min}$ intertrial intervals.

Electrophysiology. Sagittal slices (200- $\mu$ m-thick) were cut from 14- to 23-d-old mouse cerebella and perfused with oxygenated solution containing (in mM): $125 \mathrm{NaCl}, 2.5 \mathrm{KCl}, 2.5 \mathrm{CaCl}_{2}, 26.2 \mathrm{NaHCO}_{3}, 1.3$ $\mathrm{MgSO}_{4}, 1.0 \mathrm{NaH}_{2} \mathrm{PO}_{4}, 20 \mathrm{D}$-glucose, and 0.01 bicucculine methiodide (Sigma, St. Louis, MO). Whole-cell patch-clamp recordings were made from Purkinje cell somata within $6 \mathrm{hr}$ of slice preparation using pipettes $(1.5-2.5 \mathrm{M} \Omega$ ) filled with a solution containing (in $\mathrm{mM}$ ): 130 potassium gluconate, $2 \mathrm{NaCl}, 4 \mathrm{MgCl}_{2}, 4 \mathrm{Na}_{2}$-ATP, $0.4 \mathrm{Na}$-GTP, 10 sodium phosphocreatine, 20 HEPES, and 10 EGTA, pH 7.3. Parallel fiber (PF) EPSCs were elicited by applying $0.5 \mathrm{msec}$ stimuli through a thin $(2-4 \mu \mathrm{m}$ tip diameter) glass pipette placed on the slice surface in the molecular layer. Stimuli were generated by a Grass Instruments (Quincy, MA) S48 stimulator and varied between 0 and $10 \mu \mathrm{A}$. Similar stimuli applied in the granule cell layer were used to induce climbing fiber (CF) EPSCs. Software developed by Dr. W. W. Anderson (University of Bristol, Bristol, UK) was used for data acquisition.

\section{RESULTS}

\section{Biochemical changes in Camk4 ${ }^{-1-}$ cerebella}

Western blot analysis of cerebellar extracts confirmed the absence of the CaMKIV protein in cerebellum of $\mathrm{Camk}^{-/-}$mice (Fig. 1a). Levels of the other CaMKs, including CaMKI (Fig. 1b), CaMKII $\alpha$ (Fig. 1c), and CaMKK (Fig. 1d), were similar in cerebella from null, heterozygous, and WT mice. In addition, the levels of PKA, a kinase that shares common substrates with CaMKIV, including CREB (Matthews et al., 1994), were also unchanged (data not shown). This established that the disruption of the mouse CaMKIV gene was not associated with compensatory changes in $\mathrm{CaMKs}$ or kinases, such as PKA, that phosphorylate substrates of CaMKIV.

We next examined the phosphorylation of CREB, a proposed neuronal substrate for CaMKIV, in the mutant mice. Mice were placed in either a familiar or an unfamiliar environment and allowed to explore for $2 \mathrm{~min}$. The animals were then killed immediately, and the levels of CREB ( $\alpha$-CREB) and phosphorylated CREB ( $\alpha$-pCREB) were assessed by immunoblotting of cerebellar extracts. Although the total level of CREB protein was unchanged in all samples (Fig. 1e, $\alpha-C R E B$ ), the levels of phosphorylated CREB were markedly lower (fourfold) in the Camk $4^{-/-}$mice than in either WT or heterozygous mice, regardless of the environment (Fig. 1e, $\alpha-p C R E B$ ). However, in each case, placing the mice in an unfamiliar environment resulted in an increase in phosphorylated CREB relative to the familiar environment. These data suggest that the absence of CaMKIV con-
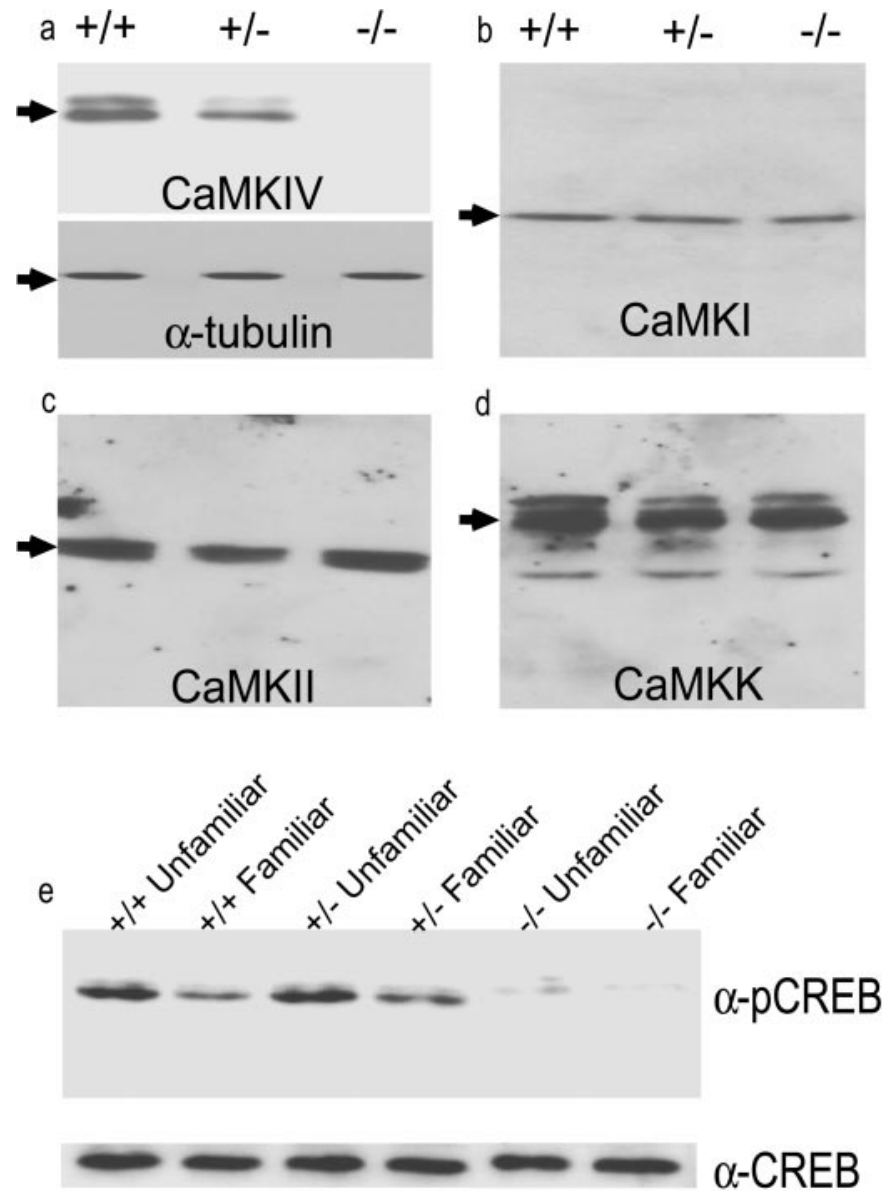

Figure 1. Loss of CaMKIV does not change the expression of other related $\mathrm{Ca}^{2+} / \mathrm{CaM}$-dependent enzymes. $a$, CaMKIV is absent in the cerebellum from null mice. $b-d$, CaMKI, CaMKII, and CaMKK expression levels in the null and heterozygous mice are not significantly different from wild-type mice. $e$, pCREB is reduced in Camk4 ${ }^{-1-}$ mice. Mice were placed in a familiar or an unfamiliar environment and allowed to explore for $2 \mathrm{~min}$. Western blots of equivalent aliquots of cerebellar extract $(25 \mu \mathrm{g}$ of protein) were used to assess either total CREB protein $(\alpha-C R E B)$ or phosphorylated CREB $(\alpha-p C R E B)$.

tributed to a significant reduction of CREB phosphorylation in the cerebellum, consistent with the proposed role of CaMKIV as a CREB kinase in cerebellar neurons.

\section{Multiple behavioral defects in Camk4 ${ }^{-/-}$mice}

On initial inspection, the Camk4 $4^{-1-}$ mice demonstrated an unusual upright posture, and $>80 \%$ of the null mice exhibited moderate tremors. When raised by their tails, the null mice clasped their hind legs close to their body, unlike WT and Camk $4^{+/-}$animals that splayed their legs outward. Because this is suggestive of ataxia (Steinmayr et al., 1998), we examined the walking gait of the null mice using a footprinting test (Fig. $2 a$ ). Although no difference in stride length was observed, there was a significant alteration in the angle of rear-paw deflection (Fig. 2a) (Robbins, 1985). The lack of symmetry between the left and right angles of rear-paw deflection (Fig. 2b) indicated that the Camk4 $4^{-1-}$ mice were ataxic, possibly because of a deficit in the organization and execution of planned movements.

Camk4 $4^{-1-}$ and WT littermates were next subjected to a battery of additional behavioral tests. In an open field environment, both spontaneous horizontal (locomotor) and vertical (rearing) activities were significantly reduced in the null mice compared with their controls (Fig. 2c,d). A behavioral screen for gross defects in motor performance was also administered (Rogers et al., 1997; 
a
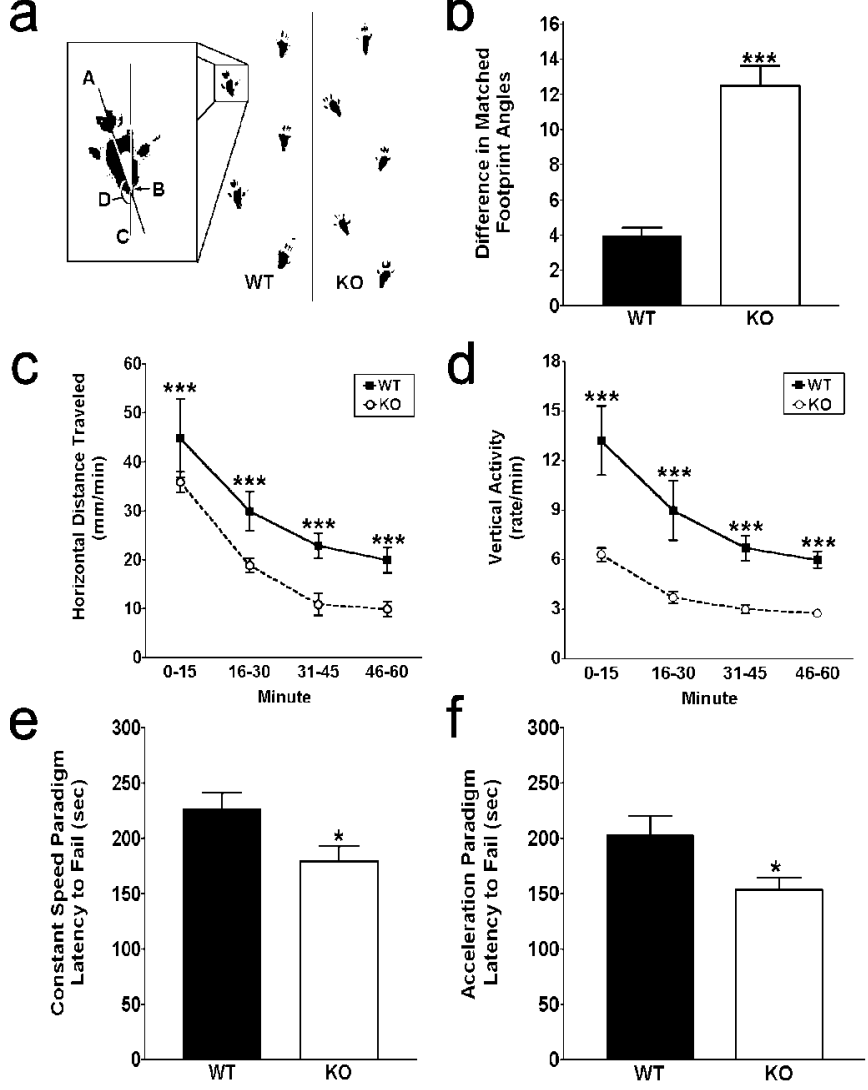

Figure 2. Assessments of spontaneous activity and motor skills in WT and $C a M K 4^{-1-}$ mice. $a, b$, Tests of ataxic responses conducted using footprinting analyses. Physiological landmarks: $A$, medial longitudinal axis of the footprint; $B$, stride (a continuous line that connected the pternions of sequential footprints); $C$, pternion (most posterior point on the print midline at which the heel strikes the blotter); $D$, angle of foot deflection at which the longitudinal axis and stride line intersect at pternion. ${ }^{* *} p<0.001$ by a one-tailed independent samples $t$ test; $n=8$. $c, d$, Spontaneous locomotor and rearing activity in the open field. The activity data are collapsed across 1 min observations and displayed in four 15 min intervals over a $1 \mathrm{hr}$ period. ${ }^{* * *} p<0.001$ by repeated measures ANOVA tests; $n=8 . e, f$, Rotorod tests of complex motor skills using the accelerated and constant-speed paradigms. ${ }^{*} p<0.05$ by a one-tailed independent samples $t$ test; $n=10$. KO, Knock-out mice.

Paylor et al., 1998). In multiple tests, the null mice were uncoordinated when attempting to grasp a vertical wire with their hindfeet and were unable to maintain their grip when the wire was gently pulled away. Mutants also could not remain suspended from a vertical wire. Compared with WT mice, $>85 \%$ of the null mice were uncoordinated in their attempts to hang from the wire with their forepaws and often grasped their face with their hindfeet (data not shown). Camk $4^{-1-}$ mice also took significantly longer than the WT controls to climb down a pole, turn around, and climb back up the pole (data not shown), and most null mice fell from the pole when trying to turn around. To analyze complex sensorimotor function, the mice were tested on a rotorod. In both acceleration (Fig. 2e) and constant-speed (Fig. 2f) paradigms, there was a significant impairment in the ability of the $\mathrm{Camk}^{-1-}$ mice to remain on the rod. All Camk4 ${ }^{-1-}$ mice frequently dragged their hindlimbs on the drum. Collectively, our behavioral results indicate that the Camk4 $4^{-1-}$ mouse is characterized by deficiencies in balance, coordination, and sensorimotor function. These impairments contribute to the overall ataxia and hypoactivity of the Camk $4^{-/-}$mice, potentially implicating cerebellar deficits as a cause of this behavioral phenotype.
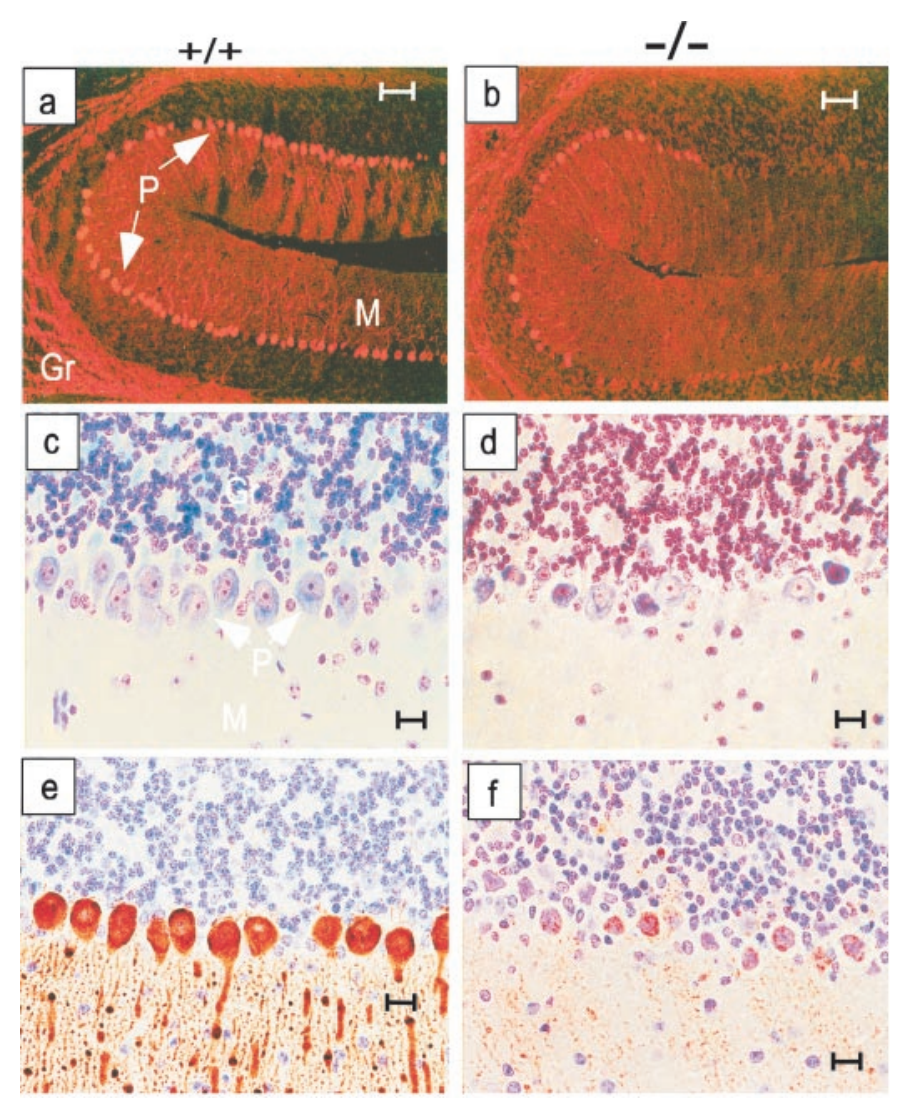

Figure 3. Structural analysis of the cerebellum from wild-type and Camk4 ${ }^{-1-}$ mice. $a, b$, Coronal sections through a representative cerebellar foliation immunostained with anti-calbindin D28k. Note the similarity in the general organization of the three cortical layers $(M$, molecular; $P$, Purkinje; $G r$, granule cell) and the apparent lack of reactive Purkinje cells. Scale bars, $50 \mu \mathrm{m}$. $c, d$, Enlarged view of the region visualized with cresyl violet confirming that there is a reduction in the number of cells that resemble mature Purkinje cells. Scale bars, $20 \mu \mathrm{m}$. $e, f$, Immunostaining demonstrating that there is a major reduction of calbindin D28k, which is a calcium binding protein expressed in the mature Purkinje cell. Scale bars, $20 \mu \mathrm{m}$.

\section{Defects in cerebellar Purkinje cells}

CaMKIV is expressed in both the Purkinje and granule cells of the cerebellum (Ohmstede et al., 1989; Jensen et al., 1991). Gross inspection of the cerebellar architecture revealed no difference in size or organization of the three layers of the cerebellar cortex at $25 \mathrm{~d}$ of age between WT or Camk4 ${ }^{-1-}$ mice (data not shown). There was, however, a pronounced decrease in the number of Purkinje cells in the mutant mice (Fig. 3a,b). The remaining Purkinje cells were smaller in size and exhibited a reduced cytoplasmic/nuclear volume relative to Purkinje cells in the WT mice (Fig. $3 c, d$ ). This observation was strengthened by immunostaining for calbindin D28k, a protein marker of differentiated Purkinje cells (Celio, 1990). As shown in Figure 3, $e$ and $f$, there was a profound reduction in calbindin D28k immunoreactivity in the Camk4 ${ }^{-1-}$ Purkinje cells. These data indicate that the absence of CaMKIV results in a decreased number of Purkinje cells and that the remaining cells exhibit immature morphological characteristics. Consistent with this possibility, our preliminary efforts to visualize dendrites suggest that the arbor is much less developed in the mutant mice (data not shown).

\section{Electrophysiology of cerebellar Purkinje cells}

To assess the role of CaMKIV in synaptic transmission in the cerebellum, we examined the responses at both $\mathrm{PF}$ and $\mathrm{CF}$ synapses that innervate the Purkinje cells. In cerebellar slices 

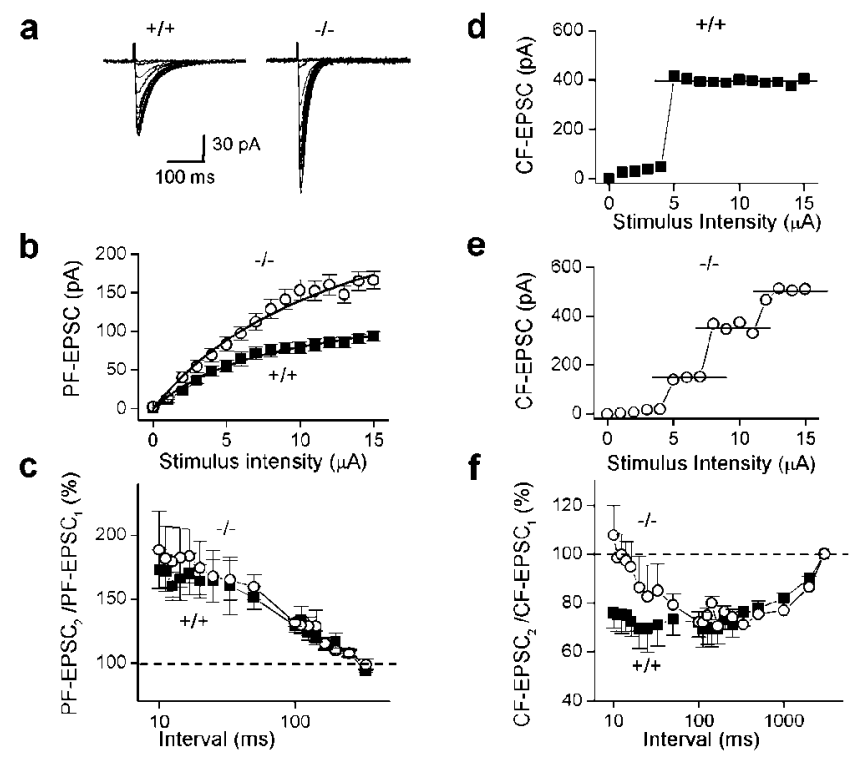

Figure 4. Purkinje cell synaptic transmission. $a$, PF-EPSCs induced by stimuli of varying intensities in slices from WT $(+/+)$ and mutant $(-/-)$ mice. $b$, Dependence of PF-EPSC amplitude on stimulus intensity for WT (filled symbols) and Camk4 $4^{-1-}$ (open symbols) mice. c, Magnitude of paired-pulse facilitation (expressed as ratio of amplitudes of second and first EPSCs) at varying interstimulus intervals. Filled symbols indicate data from WT mice, and open symbols refer to those from Camk $4^{-1-}$ mice. $d$, All-or-none dependence of CF-EPSC amplitude on stimulus intensity, measured in a WT Purkinje cell. $e$, Multiple CF innervation in a Camk $4^{-1-}$ Purkinje cell, indicated by multiple steps in the amplitude of CF-EPSCs as stimulus intensity is varied. $f$, Synaptic plasticity induced by pairs of CF stimuli in Purkinje cells from WT (filled symbols) and Camk4 $^{-1-}$ (open symbols) mice.

from both WT and Camk4 $4^{-1-}$ mice, graded electrical stimulation of the molecular layer produced graded postsynaptic currents (PF-EPSCs) attributable to recruitment of multiple parallel fiber synapses (Fig. 4a) (Konnerth et al., 1990). However, PF-EPSCs were more rapid in the Camk4 ${ }^{-1-}$ Purkinje cells (Fig. 4a), with mean rise times of $1.6 \pm 0.02$ msec compared with $2.1 \pm 0.06$ msec in the WT cells ( $p<0.05 ; t$ test) and decay time constants of $23 \pm 0.4 \mathrm{msec}$ compared with $36 \pm 0.9 \mathrm{msec}$ in WT cells $(p<$ 0.05). The amplitude of PF-EPSCs also was larger in the mutant cells at all stimulus intensities (Fig. 4b). In cells from both WT and $\mathrm{Camk}^{-1-}$ mice, paired stimuli evoked synaptic facilitation that was not significantly affected by the absence of CaMKIV (Fig. 4c). These results are consistent with the idea that elimination of the Camk4 gene affects PF transmission indirectly by altering the size and electrotonic length of the postsynaptic Purkinje cell rather than by altering the ability of the PF to release neurotransmitter (Llano et al., 1991).

The properties of CF synapses also were affected in the Camk4 ${ }^{-1-}$ mice. Multiple CF inputs are common in developing Purkinje cells but are eliminated during synaptic development (Crepel et al., 1976). In each of nine recordings from WT Purkinje cells, stimulation of the granule cell layer produced a single all-or-none EPSC that is characteristic of the mature CF synapse (Konnerth et al., 1990) (Fig. 4d). Although this situation was recapitulated for some Camk4 ${ }^{-/}$Purkinje cells, in three of eight cases, we observed multiple CF innervation that was evident as discrete steps in the relationship between stimulus intensity and CF-EPSC amplitude (Fig. 4e). The difference in the occurrence of multiple CF innervation between $\mathrm{WT}$ and Camk4 ${ }^{-1-} \mathrm{CF}$ synapses is significant $\left(p<0.05 ; \chi^{2}\right.$ test $)$, indicating that the Camk $4^{-/-}$Purkinje cells have an immature synaptic architecture. CF synapses from Camk4 $4^{-1-}$ mice exhibiting multiple innervation produced CF-EPSCs of $136 \pm 32 \mathrm{pA}$ in amplitude, which was significantly smaller than the amplitude of CF-EPSCs recorded in WT animals $(348 \pm 34 \mathrm{pA} ; p<0.01)$ or in those from Camk4 $4^{-1-}$ Purkinje cells that were singly innervated $(356 \pm 35 \mathrm{pA} ; p<$ $0.05)$. Likewise, the short-term plasticity of CF synapses is altered in the absence of CaMKIV. WT animals exhibited a pronounced synaptic depression after paired CF stimuli (Konnerth et al., 1990), whereas in the Camk4 $4^{-/-}$mice, there was an initial net facilitation, followed by depression at longer stimulus intervals (Fig. 4f). This change in the dynamic properties of the CF synapse suggests a smaller release of neurotransmitter from the CF synapses that are multiply innervating the Purkinje cell (Hashimoto and Kano, 1998). In summary, loss of CaMKIV alters transmission at both of the excitatory synapses on the Purkinje cell, characteristics consistent with an immature structural development of the cerebellar cortex in the mutant animals.

\section{DISCUSSION}

A number of lines of evidence have implicated CaMKIV in the control of gene transcription (Bito et al., 1996; Anderson et al., 1997; Westphal et al., 1998; Ahn et al., 1999). On the other hand, developmentally regulated changes in the pattern of CaMKIV expression coupled with the subcellular localization to the nucleus and cytosol hints at a wider role for this kinase in growth and differentiation of specific cell types and in synaptic plasticity of neurons. By generating CaMKIV null mice, we have established a key role for this kinase. Adult mutant mice were ataxic and performed poorly on numerous behavioral tests, suggesting significant cerebellar dysfunction. Biochemical and morphological studies established that cerebellar Purkinje cells in the mutant mice are less abundant, smaller in size, and expressed less calbindin D28k than normal. Moreover, physiological studies demonstrated electrophysiological modifications in transmission at both PF and CF synapses on the remaining Purkinje cells, consistent with the failure of these cells to reach full maturation. Together, these data suggest that CaMKIV has an important role in the function and development of cerebellar Purkinje cells.

Although CaMKIV has been proposed to regulate the activity of a number of different transcription factors (Chawla et al., 1998; Youn et al., 1999), CREB is the only known direct substrate for the enzyme (Matthews et al., 1994). Our demonstration of defects in CREB phosphorylation (Fig. 1e) suggests that this protein may be involved in the actions of CaMKIV within the cerebellum. However, it remains unclear whether the decrease in phosphorylated CREB is attributable to altered development of Purkinje cells, abnormalities in excitatory transmission in the cerebellum, lack of an essential CREB kinase activity or other causes. In cultured embryonic Purkinje cells, CaMKIV can regulate the CREB-dependent phase of long-term depression (LTD), a mechanism that weakens the PF synapse (Ahn et al., 1999). On the other hand, CaMKIV is not detectable in Purkinje cells in WT rodents older than $14 \mathrm{~d}$ (Jensen et al., 1991). Hence, although the reduction of LTD may affect cerebellar function, it is unlikely to be the primary mechanism for the decreased number and immature development of Purkinje cells. A quantitative analysis of the number of Purkinje cells present in WT and Camk4 ${ }^{-1-}$ mice as a function of age will be required to address this question.

Targeted gene mutations in a number of signaling molecules, such as calbindin D28k (Airaksinen et al., 1997), phospholipase C $\beta 4$ (Kano et al., 1998), or G $\alpha$ q (Offermanns et al., 1997), yields phenotypic changes somewhat similar to what we have described for the Camk4 $4^{-1-}$ mice. However, only one other mutant mouse has exhibited the panoply of defects that we have observed in the CaMKIV null mouse. Deletion of $\operatorname{ROR} \alpha$, an orphan member of the steroid receptor super family of transcription factors, results in the loss of motor control, a decrease in the number of Purkinje cells, immature development of the remaining Purkinje cells, and multiple innervation of these cells by CFs (Dussault et al., 1998; Steinmayr et al., 1998). Mutation of the ROR $\alpha$ gene also causes 
the staggerer mouse, whose phenotype is strikingly similar to the Camk4 $^{-1-}$ mice (Hamilton et al., 1996). CaMKIV markedly increases transcriptional activity by $\mathrm{ROR} \alpha$ in transient transfection assays (Kane and Means, 2000), and $\operatorname{ROR} \alpha$ acts as a transcription factor to regulate expression of genes encoding markers of differentiated Purkinje cells (Matsui, 1997). In addition, both ROR $\alpha$ and CaMKIV are expressed in Purkinje cells early in development (Jensen et al., 1991; Vogel et al., 2000). Thus, it is quite possible that $\operatorname{ROR} \alpha$ is a key downstream target of CaMKIV in the cerebellar Purkinje cells and that defects in CaMKIV-ROR $\alpha$ signaling yield many of the abnormalities in the Camk4 ${ }^{-1-}$ mice.

In summary, our results establish CaMKIV as a component of a signal transduction pathway that leads to the terminal differentiation of Purkinje cells. Other experiments using Camk4 $4^{-1-}$ mutants have revealed that CaMKIV is also critical in controlling the development of T lymphocytes (Anderson et al., 1997) and postmeiotic maturation of male germ cells (Wu et al., 2000). Collectively, the results indicate that a developmental delay is a common consequence of deleting the CaMKIV gene and suggests that CaMKIV may be a general regulator of the terminal differentiation of precursors into specialized cells. Further analysis of the CaMKIV null mice should provide new information on the role of this calcium-regulated protein kinase in the brain and other mammalian tissues.

Note added in proof. After acceptance of our manuscript, a paper was published by Ho et al. (2000). These authors independently created mice null for the CaMKIV gene and found deficits in CREB phosphorylation in several areas of the brain, consistent with what we have found in the cerebellum of mutant mice. These studies also revealed that Purkinje cells cultured from embryonic Camk4 ${ }^{-1-}$ mice are deficient in a late phase of LTD, which complements our observations of alterations in synaptic transmission in CaMKIV-deficient mice.

\section{REFERENCES}

Ahn S, Ginty DD, Linden DJ (1999) A late phase of cerebellar longterm depression requires the activation of CaMKIV and CREB. Neuron 23:559-568.

Airaksinen MS, Eilers J, Garaschuk O, Thoenen H, Konnerth A, Meyer M (1997) Ataxia and altered dendritic calcium signaling in mice carrying a targeted null mutation of the calbindin D28k gene. Proc Natl Acad Sci USA 94:1488-1493.

Anderson KA, Ribar TJ, Illario M, Means AR (1997) Defective survival and activation of thymocytes in transgenic mice expressing a catalytically inactive form of $\mathrm{Ca}^{2+} /$ calmodulin-dependent protein kinase IV. Mol Endocrinol 11:725-737.

Bito H, Deisseroth K, Tsien RW (1996) CREB phosphorylation and dephosphorylation: a $\mathrm{Ca}(2+)$ - and stimulus duration-dependent switch for hippocampal gene expression. Cell 87:1203-1214.

Celio MR (1990) Calbindin D-28k and parvalbumin in the rat nervous system. Neuroscience 35:375-475.

Chawla S, Hardingham GE, Quinn DR, Bading H (1998) CBP: a signalregulated transcriptional coactivator controlled by nuclear calcium and CaM kinase IV. Science 281:1505-1509.

Crepel F, Mariani J, Delhaye-Bouchaud N (1976) Evidence for a multiple innervation of Purkinje cells by climbing fibers in the immature rat cerebellum. J Neurobiol 7:567-578.

Dussault I, Fawcett D, Matthyssen A, Bader JA, Giguere V (1998) Orphan nuclear receptor $\operatorname{ROR} \alpha$-deficient mice display the cerebellar defects of staggerer. Mech Dev 70:147-153.

Frangakis MV, Chatila T, Wood ER, Sahyoun N (1991) Expression of a neuronal $\mathrm{Ca}^{2+} /$ calmodulin-dependent protein kinase, CaM kinaseGR, in rat thymus. J Biol Chem 266:17592-17596.

Hamilton BA, Frankel WN, Kerrebrock AW, Hawkins TL, FitzHugh W, Kusumi K, Russell LB, Mueller KL, van Berkel V, Birren BW, Kruglyak L, Lander ES (1996) Disruption of the nuclear hormone receptor ROR $\alpha$ in staggerer mice. Nature 379:736-739.

Hashimoto K, Kano M (1998) Presynaptic origin of paired-pulse depression at climbing fiber-Purkinje cell synapses in the rat cerebellum. J Physiol (Lond) 506:391-405.

Ho N, Liauw JA, Blaeser F, Wei F, Hanissian S, Muglia LM, Wozniak DF, Nardi A, Arvin KL, Holtzman DM, Linden DJ, Zhuo M, Muglia
LJ, Chatila TA (2000) Impaired synaptic plasticity and cAMP response element-binding protein activation in $\mathrm{Ca}^{2+} /$ calmodulindependent protein kinase type IV/Gr-deficient mice. J Neurosci 20:6459-6472.

Jensen KF, Ohmstede CA, Fisher RS, Olin JK, Sahyoun N (1991) Aquisition and loss of a neuronal $\mathrm{Ca}^{2+} /$ calmodulin-dependent protein kinase during neuronal differentiation. Proc Natl Acad Sci USA $88: 4050-4053$

Kane CD, Means AR (2000) Activation of orphan receptor-mediated transcription by $\mathrm{Ca}(2+) /$ calmodulin-dependent protein kinase IV. EMBO J 19:691-701.

Kano M, Hashimoto K, Watanabe M, Kurihara H, Offermanns S, Jiang H, Wu Y, Jun K, Shin HS, Inoue Y, Simon MI, Wu D (1998) Phospholipase $\mathrm{c} \beta 4$ is specifically involved in climbing fiber synapse elimination in the developing cerebellum. Proc Natl Acad Sci USA 95:15724-15729.

Konnerth A, Llano I, Armstrong CM (1990) Synaptic currents in cerebellar Purkinje cells. Proc Natl Acad Sci USA 87:2662-2665.

Llano I, Marty A, Armstrong AM, Konnerth A (1991) Synaptic and agonist-induced excitatory currents of Purkinje cells in rat cerebellar slices. J Physiol (Lond) 434:183-213.

Masaaki T, Bushra A, Yun-Fei L, Hideki M, Osamu M, Fuminori Y, Ryoji K, Osamu H (1997) Involvement of calmodulin-dependent protein kinases-I and -IV in long-term potentiation. Brain Res 755:162-166

Matsui T (1997) Transcriptional regulation of a Purkinje cell-specific gene through a functional interaction between $\operatorname{ROR} \alpha$ and $\operatorname{RAR}$. Genes Cells 2:263-272.

Matthews RP, Guthrie CR, Wailes LM, Zhao X, Means AR, McKnight GS (1994) Calcium/calmodulin-dependent protein kinases type II and type IV differentially regulate CREB-dependent gene expression. Mol Cell Biol 14:6107-6116.

Means AR (2000) Regulatory cascades involving calmodulin-dependent protein kinases. Mol Endocrinol 14:4-13.

Means AR, Cruzalegui F, LeMagueresse B, Needleman DS, Slaughter GR, Ono $\mathrm{T}$ (1991) A novel $\mathrm{Ca}^{2+} /$ calmodulin-dependent protein kinase and a male germ cell-specific calmodulin-binding protein are derived from the same gene. Mol Cell Biol 11:3960-3971.

Offermanns S Hashimoto K, Watanabe M, Sun W, Kurihara H, Thompson RF, Inoue Y, Kano M, Simon MI (1997) Impaired motor coordination and persistent multiple climbing fiber innervation of cerebellar Purkinje cells in mice lacking G $\alpha \mathrm{q}$. Proc Natl Acad Sci USA 94:14089-14094.

Ohmstede CA, Jensen KF, Sahyoun NE (1989) $\mathrm{Ca}^{2+} /$ calmodulindependent protein kinase enriched in cerebellar granule cells. Identification of a novel neuronal calmodulin-dependent protein kinase. J Biol Chem 264:5866-5875.

Paylor R, Nguyen M, Crawley JN, Patrick J, Beaudet A, Orr-Urtreger A (1998) $\alpha 7$ nicotinic receptor subunits are not necessary for hippocampal dependent learning or sensorimotor gating: a behavioral characterization of Acra7-deficient mice. Learn Mem 5:302-316.

Robbins LM (1985) Footprints: collection, analysis, and interpretation. Spingfield, IL: Thomas.

Rogers DC, Fisher EMC, Brown SDM, Peters J, Hunter AJ, Martin JE (1997) Behavioral and functional analysis of mouse phenotype: SHIRPA, a proposed protocol for comprehensive phenotype assessment. Mamm Genome 8:711-713.

Schulman H, Braun A (1999) Calcium/calmodulin-dependent protein kinases. In: Calcium as a cellular regulator (Carafoli E, Klee C, eds), pp 311-343. New York: Oxford UP.

Shieh PB, Hu SC, Bobb K, Timmusk T, Ghosh A (1998) Identification of a signaling pathway involved in calcium regulation of BDNF. Neuron 20:727-740

Silva A, Paylor R, Wehner J, Tonegawa S (1992) Impaired spatial learning in $\alpha$-calcium-calmodulin kinase II mutant mice. Science 257:206-210

Steinmayr M, Andre E, Conquet F, Rondi-Reig L, DelHaye-Bouchaud N, Auclair N, Daniel H, Crepel F, Mariani J, Sotelo C, Becker-Andre M (1998) Staggerer phenotype in retinoid-related orphan receptor $\alpha$-deficient mice. Proc Natl Acad Sci USA 95:3960-3965.

Vogel MW, Sinclair M, Qiu D, Fan H (2000). Purkinje cell fate in staggerer mutants: agenesis versus cell death. J Neurobiol 42:323-337.

Westphal RS, Anderson KA, Means AR, Wadzinski BE (1998) A signaling complex of $\mathrm{Ca}^{2+} /$ calmodulin-dependent protein kinase IV and protein phosphatase 2A. Science 280:1258-1261.

Wu JY, Ribar TJ, Cummings DE, Burton KA, McKnight GS, Means AR (2000) Spermiogenesis and exchange of basic nuclear proteins are impaired in male germ cells lacking $\mathrm{Ca}^{2+} /$ calmodulin-dependent protein kinase IV. Nat Genet 25:448-452.

Youn HD, Sun L, Prywes R, Liu JO (1999) Apoptosis of T-cells mediated by $\mathrm{Ca}^{2+}$-induced release of the transcription factor MEF2. Science 286:790-793. 